\title{
Keberlanjutan Instalasi Pengolahan Air Limbah Domestik (Ipal) Berbasis Masyarakat, Gunung Kidul, Yogyakarta
}

\author{
Ridwan Hafidh, Fibriliana Kartika, Aulia Ulfah Farahdiba \\ Program Studi Teknik Lingkungan, Universitas Islam Indonesia \\ Jl. Kaliurang Km 14,5 Yogyakarta 55584 Telp 0274-896440 \\ Email: auliaulfahfarahdiba@gmail.com ; a.ulfah@uii.ac.id
}

\begin{abstract}
Abstrak
Aplikasi teknologi dengan memperhatikan aspek komunitas menjadi salah satu faktor yang signifikan dalam keberlangsungan instalasi pengolahan air limbah. Penelitian ini dilakukan pada Dusun Mendak Giri Sekar, Kecamatan Gunung Kidul dengan kapasitas untuk dua RT(62 KK). Studi ini melihat aspek sosial, ekonomi, dan lingkungan dari proses pembangunan hingga pengoperasian IPAL yang dilakukan oleh warga. Kajian kelayakan lingkungan dilakukan dengan menganalisis efluent limbah domestik di IPAL. Studi dilakukan dengan survey lapangan dan wawancara terhadap masyarakat beserta tokoh penanggungjawab daerah. Penelitian ini menganalisis faktor-faktor penting yang berhubungan dalam pembangunan dan pengoperasian IPAL beserta menganalisis tingkat keberlanjutan teknologi melihat dari peran masyarakat, pemerintah, dan stakeholder. Sehingga, peningkatan pemberdayaan masyarakat menjadi salah satu tolak ukur kesuksesan dalam mengelola dan mengentaskan permasalahan sanitasi yang ada di Indonesia. Pada tahap pembangunan hingga pengoperasian, sudah melibatkan partisipasi masyarakat. Retribusi IPAL menjadi kesepakatan mufakat yang diterapkan di desa ini. Selain itu, analisis kualitas yang dilakukan telah memenuhi parameter kualitas air limbah. Dengan adanya penggunaan IPAL masyarakat dapat merasakan lingkungan menjadi lebih baik, sehingga menimbulkan rasa kepemilikan oleh warga.
\end{abstract}

Kata Kunci : SANIMAS ,Air Limbah, IPAL, Keberlanjutan

\begin{abstract}
Community-based became the significant factors in the sustainability of wastewater treatment plants. This research was conducted at the Dusun Mendak Giri Sekar, District of Gunung Kidul with a capacity for two RT (62 household). This study developed at the social, economic, and environment of the development process to the WWTP operation carried out by the residents. Environmental feasibility study carried out by analyzing domestic waste in WWTP effluent. The study was conducted by field surveys and interviews with community and leaders in charge of the area. Analyzes the critical factors related to the construction and operation of wastewater along with analyzing the sustainability level of technology view of the role of communities, governments, and stakeholders. An increase empowerment of communities became critical factor of success in managing and alleviating the problem of sanitation in Indonesia. At this stage of development to the operation, already involve public participation. Retribution WWTP into consensus agreements are applied in this village. In addition, the quality of the analysis performed in compliance with the waste water quality parameters. People can perceive the improvement of environment with WWTP, lead to a sense of ownership by the residents.
\end{abstract}

Keywords: SANIMAS, Wastewater, WWTP, Sustainability

Dikirim/submitted: 8 Desember 2015

Diterima/accepted: 5 Januari 2016 


\section{PENDAHULUAN}

Pertumbuhan penduduk kota yang tinggi serta meningkatnya kegiatan pembangunan diberbagai sektor menimbulkan berbagai masalah di wilayah-wilayah perkotaan yang antara lain urbanisasi, permukiman kumuh, pencemaran air limbah dan sebagainya. Permasalahan yang dialami hampir di seluruh kota di Indonesia adalah pencemaran air limbah (BPPT, 2008).

Penanganan air limbah yang selama ini dilakukan belum sampai pada tahap pemikiran proses penanganan atau menggunakan ulang limbah tersebut. Penanganan limbah yang selama ini hanya dilakukan dengan cara kuratif, yaitu dengan mengolah air limbah yang dibuang ke lingkungan. Cara seperti ini kurang bisa mengatasi masalah pencemaran air limbah karena masih dapat menimbulkan pencemaran lingkungan (Hammer, 1985 dan Kusnoputranto, 1983).

Dusun Mendak, Giri Sekar, Gunung Kidul sebagai dusun yang dikenal dengan kualitas pertanian, dan perdagangan yang cukup baik. Namun, dusun ini menjadi salah satu daerah yang memiliki masalah air limbah domestik. Selain itu, pemilihan lokasi ini didasarkan atas pertimbangan bahwa sistem pengelolaan air limbah di Dusun Mendak, Giri Sekar sebelumnya tidak berjalan baik. Instalasi Pengolahan Air Limbah (IPAL) tersebut dibangun oleh Dinas Pekerjaan Umum Perumahan Energi dan Sumber Daya Mineral (ESDM), Provinsi Daerah Istimewa Yogyakarta pada tahun 2014. Pembangunan IPAL sebagai salah satu solusi untuk mengatasi permasalahn berikut. Keberlanjutan teknologi yang diterapkan diharapkan sudah melibatkan masyarakat mulai dari tahap pembangunan hingga operasi IPAL (Puspita, 2008). Namun, dalam pengoperasiannya IPAL tersebut mengalami beberapa masalah teknis. Beberapa kendala yang dihadapi di dalam menggunakan kembali air, limbah yakni karena air limbah perkotaan kualitasnya tidak memenuhi syarat kualitas air untuk berbagai keperluan yakni mengandung unsur polutan yang cukup besar oleh karena itu sebelum digunakan kembali (reuse) perlu dilakukan pengolahan sampai mencapai syarat kualitas yang diperbolehkan (Mahida, 1986 dan Sugiharto, 1987). Selain itu, peran serta masyarakat sangat berpengaruh dalam keberlanjutan operasi dan kualitas air limbah dari IPAL.

\section{GAMBARAN UMUM WILAYAH STUDI}

Pada tahun 2014, Dusun Mendak, Giri Sekar, Gunung Kidul mulai berkembang dengan tanah Kas desa yang disediakan dan digunakan oleh warga untuk pembuatan Ipal Komunal yang telah dilakukan oleh DPUP ESDM Provinsi D.I.Yogyakarta. Dusun Mendak merupakan salah satu Dusun di Kabupaten GiriSekar. Sebelum adanya pembangunan IPAL, pada musim hujan sering 
terjadi genangan air limbah di sekitar rumah warga. Secara umum, kondisi pencemaran air limbah dapat dikatakan tidak ada masalah yang sangat serius. Namun tetap saja menimbulkan beberapa dampak negatif bagi lingkungan. Dusun menjadi kumuh, lingkungan menjadi bau, tidak sehat, dan sebagai tempat berkembangbiaknya sumber penyakit.

Agar tidak berperan sebagai sumber penularan penyakit., tinja harus dibuang dengan cara ditampung serta diolah pada suatu lubang dalam tanah atau bak tertutup tidak terjangkau oleh lalat dan tikus, serta harus berjarak minimal 15 meter dari sumber air minum. Limbah cair dapat boleh dibuang ke lingkungan tanah atau badan air setelah melalui proses pengolahan yang dapat menekan kandungan bahan pencemarnya sampai tingkat tertentu yang sesuai dengan baku mutu limbah cair (Said, 2003).

\subsection{Administrasi dan Kondisi Lapangan}

Berikut adalah administrasi dan kondisi lapangan Dusun Mendak, Giri Sekar.

Tabel. 2.1 Data Administrasi Dusun Mendak, Giri Sekar

\begin{tabular}{|l|l|}
\hline Provinsi & D.I.Yogyakarta \\
\hline Kabupaten / Kota & Gunung Kidul \\
\hline Lokasi & Dusun Mendak, Desa Giri Sekar, Kecamatan Panggang \\
\hline Tahun Anggaran & 2014 \\
\hline Sistem & IPAL KOMUNAL \\
\hline Status Lahan & Hibah Desa / Tanah Kas \\
\hline Luas Lahan & $200 \mathrm{M}^{2}$ \\
\hline Kemiringan Tanah & 1 \\
\hline Kondisi Permukaan Tanah & Bergelombang, Tebing \\
\hline Koordinat Lokasi & $\begin{array}{l}\text { Lattitude : } \\
8.03435\end{array}$ \\
\hline Nama KSM & Mendak Asri \\
\hline Ketua KSM & Dwi Winarno Siwi \\
\hline
\end{tabular}

Sumber:Dinas Pekerjaan Umum,2015

\subsection{Penggunaan Lahan}

Berikut adalah data penggunaan lahan Dusun Mendak, Giri Sekar 
Tabel. 2.2 Data Penggunaan Lahan Dusun Mendak, Giri Sekar

\begin{tabular}{|l|c|c|l|l|}
\hline \multicolumn{1}{|c|}{ Bangunan } & \multirow{2}{*}{ Umum } & \multirow{2}{*}{ Pribadi } & $\begin{array}{r}\text { IPAL Komunal } \\
\text { (SANIMAS) }\end{array}$ & Kondisi \\
\hline \multirow{2}{*}{ Jumlah Kamar Mandi } & 0 & \multirow{2}{*}{62} & AF (An - Aerobic Filtration) & Baik \\
\cline { 4 - 6 } & & & Settler (Bak Pengendap) & Baik \\
\hline \multirow{2}{*}{ Jumlah Cuci Tangan } & 0 & 0 & Digester & Baik \\
\cline { 4 - 6 } Jumlah Wc & \multirow{2}{*}{62} & Bak Kontrol & Bak Inlet \\
\cline { 4 - 6 } & \multirow{2}{*}{ Jumlah Cuci Pakaian } & \multirow{2}{*}{0} & Pipa Ventilasi & Sarana Perpipaan \\
\cline { 4 - 6 } & & & Pipa dan Jalur Pembuangan & Baik \\
\hline
\end{tabular}

Sumber:Dinas Pekerjaan Umum,2015

\section{METODE PENELITIAN}

Jenis data atau informasi yang akan dikumpulkan dalam penelitian ini adalah data primer dan data sekunder. Data primer adalah pengumpulan data dengan observasi langsung di lapangan/pengamatan dan wawancara, menyangkut hal-hal yang relevan dengan rumusan masalah. Sedangkan data sekunder adalah data data ini diperoleh dari instansi-instansi terkait seperti dari kantor DPUP ESDM Provinsi D.I.Yogyakarta. Selain itu, dilakukan sampling pengamatan kualitas air limbah dengan parameter air limbah domestik untuk mengetahui kinerja IPAL Dusun Mendak.

\section{KHASIL DAN PEMBAHASAN}

\subsection{Rencana Operasional 1 IPAL}

Berikut adalah data rencana operasional IPAL

Tabel. 4.1 Data Penggunaan Lahan Dusun Mendak, Giri Sekar

\begin{tabular}{|l|c|c|}
\hline & KK & JIWA \\
\hline Iuran KSM (per KK) & \multicolumn{2}{|c|}{ Rp. 10.000,- } \\
\hline Rencana Pengguna & 62 & 248 \\
\hline Realisasi Pengguna & 55 & 220 \\
\hline \multicolumn{3}{|c|}{ Sumber:Dinas Pekerjaan Umum,2015 }
\end{tabular}

Dari pengamatan yang telah dilakukan, tidak ada lagi genangan air limbah di sekitar rumah warga setelah IPAL Komunal itu dibangun. Kondisi tersebut menyebabkan lingkungan di sekitarnya menjadi nyaman, sehat, dan tidka berbau. Lingkungan juga terlihat lebih indah dan bersih. Berikut adalah gambar lokasi ipal komunal sanimas Dusun Mendak tahun 2015. 


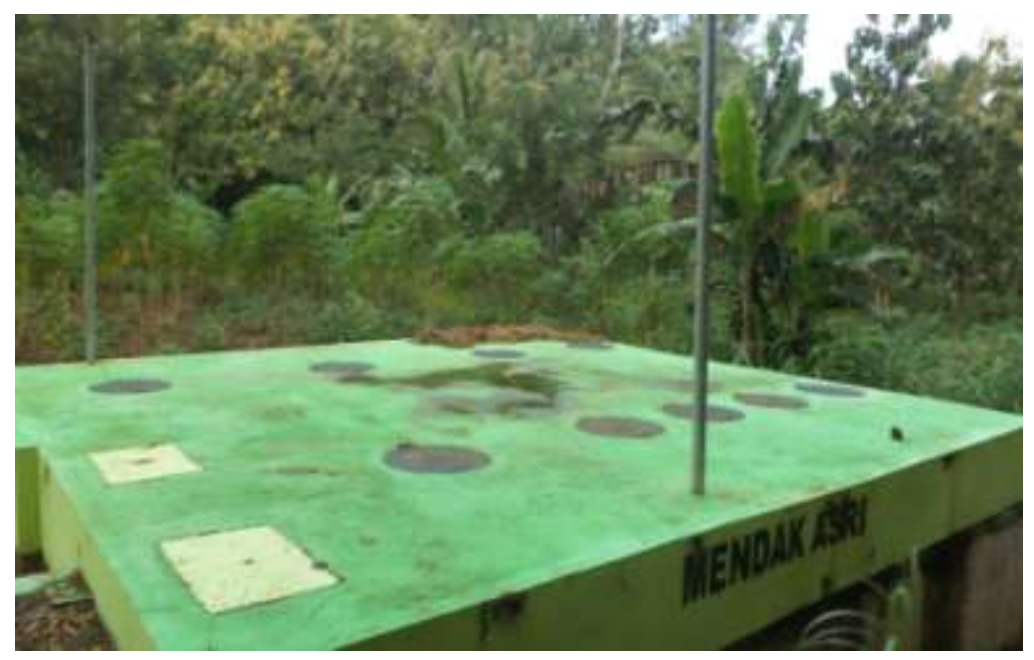

Gambar 4.1. IPAL Komunal Mendak Girisekar, Panggang, Gunung Kidul (Sumber: Hasil Pengamatan,2015)

\subsection{Kondisi Fisik}

IPAL komunal di Dusun Mendak, Giri Sekar, Gunung Kidul didirikan pada bulan Juli 2014 dengan waktu pemilihan hingga pembuatan kurang dari tiga bulan dengan kapasitas IPAL komunal adalah untuk $62 \mathrm{KK}$. dengan $55 \mathrm{KK}$ yang ikut menyambung. Pembuatan IPAL komunal di Dusun Mendak berbentuk persegi. Pada awalnya, tidak ada permasalahan di dalam IPAL komunal ini. Pada awal pengoperasian hari pertama sampai waktu dua bulan timbul bau karena adanya proses awal pengoperasian. Hingga saat ini tidak ada permasalahan yang serius. IPAL komunal di Dusun Mendak, Giri Sekar, Gunung Kidul dalam keadaan baik.

\subsection{Operasional dan Kontroling}

Dalam pengoperasian IPAL komunal, warga Dusun Mendak, Giri Sekar, Gunungkidul melakukan kontroling IPAL setiap dua hingga tiga minggu sekali yang dilakukan langsung oleh warga dalam pengontrolan IPAL komunal yaitu pengontrolan secara fisik dari luar.

Pada bak kontrol terdapat busa, hal ini kemungkinan terjadi karena banyaknya sampah plastik yang masuk pada bak inlet sehingga mengakibatkan air limbah tidak dapat masuk ke dalam unit pengolahan secara sempurna (Said, 1993). Hal ini karena masyarakat masih memiliki kebiasaan membuang sampah di WC, sehingga diperlukan adanya sosialisasi lebih lanjut mengenai operasi IPAL dalam skala rumah tangga (Haris, 2007).

\subsection{Aspek Ekonomi}

\section{1) Tingkat Pendapatan Perkapita}

Tingkat pendapatan perkapita warga cukup heterogen, sebagai petani, peternak, pedagang, hingga pegawai. Tidak terjadi permasalahan yang spesifik dikarenakan masih adanya kesadaran 
masyarakat yang cukup tinggi yang sanggup untuk menyetarakan tingkat retribusi operasional serta pengadaan rekening swadaya masyarakat.

\section{2) Kesanggupan Pembayaran Retribusi}

Warga Dusun Mendak, Giri Sekar, Gunung Kidul dalam awal perencanaan hingga operasional memerlukan dana yang tidak sedikit. Sebagian dana pembuatan didapat dari pemerintah dan sebagian lagi dana dari warga Dusun Mendak, Giri Sekar, Gunung Kidul. Setelah pembuatan selesai, warga menetapkan biaya retribusi sebesar Rp10.000,00 per KK yang menyambung di dalam IPAL Komunal.

\section{3) Pemanfaatan Pembiayaan Pengelolaan}

Dana Rp10.000,00 dari warga dusun Mendak, Giri Sekar, Gunung Kidul kemudian dimasukkan ke dalam sebuah rekening yang dikhususkan untuk operasional IPAL komunal. Uang tersebut dibayarkan selama sebulan sekali pada saat pertemuan rutin bulanan. Peruntukan selain untuk upah operator, retribusi ini juga peningkatan dan pemeliharaan sarana prasarana IPAL dan perpipaan. Pemanfaatan biaya sendiri juga dapat dialokasikan sebagai kas dana atau tabungan untuk pengembangan jangka panjang demi meningkatkan kualitas IPAL (Farahdiba (a), 2014). Seperti antisipasi kerusakan pada sarana pepipaan, sambungan perpipaan dan lain sebagainya.

\subsection{Aspek Sosial}

\section{1) Sosialisasi}

Pada awal sebelum dibuatnya IPAL komunal, warga Dusun Mendak, Giri Sekar, Gunung Kidul tertarik akan pembangunan IPAL komunal melalui sosialisasi pada saat pertemuan rutin. Warga memiliki kesadaran yang cukup tinggi, sehingga mengadakan pertemuan rutin dari pemilihan hingga pembuatan IPAL. Namun pada saat sosialisasi cukup banyak kendala yang terjadi yaitu masalah pembongkaran pipa yang tanahnya merupakan milik warga kas desa. Dengan kesadaran akan pentingnya merawat lingkungan, warga sadar untuk membongkar dan memasang kembali keramik rumah sabagai jalur perpipaan dari MCK .

\section{2) Partisipasi Masyarakat}

Dari awal perencanaan hingga Pembangunan IPAL komunal di Dusun Mendak, Giri Sekar, Gunung Kidul selalu melibatkan warga setempat. Bapak Karyoto selaku kepala pembuatan IPAL komunal SANIMAS. Patisipasi masyarakat juga mempersiapkan dari berbagai macam hal seperti pemberian konsumsi kepada masyarakat yang ikut berperan serta dalam penggarapan konstruksi IPAL komunal tersebut (Farahdiba (a), 2014 dan Farahdiba (b),2014).

\subsection{Aspek Teknis dan Lingkungan}

\section{1) Penanganan Teknis dan Kendala Teknis}


IPAL komunal SANIMAS berbentuk persegi. Pada saat pengoperasian IPAL komunal hari pertama hingga dua bulan terdapat kendala yang dirasakan warga yaitu timbulnya bau dari pipa vent. Tetapi permasalahan itu tidak berlangsung lama dan dapat dikatakan wajar karena baru awal pengoperasian. Hingga saat ini, tidak ada kendala serius yang dirasakan warga.

\section{2) Analisis Kualitas Effluent IPAL KOMUNAL}

Guna mengetahui lebih luas tentang air limbah, perlu diketahui juga secara detail mengenai kandungan yang ada dalam air limbah serta karakteristiknya. Dalam uji laboratorium dilakukan pengukuran 5 parameter kualitas air limbah, yaitu: pH, BOD, COD, TSS, dan kekeruhan. Dari hasil pengamatan dan perbandingan dengan baku mutu kualitas air limbah berdasarkan Kepmen LH 112 Tahun 2003, bahwa kualitas effluent dari IPAL Dusun Mendak Girisekar telah memenuhi baku mutu. Maka dari itu dapat disimpulkan bahwa kondisi fisik IPAL dalam mengolah air limbah masih dalam kondisi optimum.

Tabel 4.2 Hasil analisis uji laboratorium effluent IPAL

\begin{tabular}{|l|l|l|l|c|}
\hline No. & \multicolumn{1}{|c|}{ Parameter } & \multicolumn{1}{|c|}{ Nilai } & \multicolumn{1}{|c|}{ Metode pengujian } & $\begin{array}{c}\text { Baku Mutu } \\
\text { (Kepmen LH 112) }\end{array}$ \\
\hline 1. & pH & 7,59 & SNI 06-6989.11-2004 & $6-9$ \\
\hline 2. & BOD & $80,61 \mathrm{mg} / \mathrm{L}$ & SNI M 69-1990-03 & $100 \mathrm{mg} / \mathrm{L}$ \\
\hline 3. & COD & $121,85 \mathrm{mg} / \mathrm{L}$ & SNI 6986.2-2009 & - \\
\hline 4. & TSS & $132 \mathrm{mg} / \mathrm{L}$ & SNI 06-6989.3-2004 & $100 \mathrm{mg} / \mathrm{L}$ \\
\hline 5. & Kekeruhan & $11,4 \mathrm{NTU}$ & SNI 06-6989.25-2005 & - \\
\hline
\end{tabular}

Sumber: Hasil Penelitian, 2015

\section{3) Pollutin Index}

Berikut adalah hasil uji laboratorium ipal komunal sanimas Dusun Mendak, Giri Sekar tahun 2014 menurut Polution Index ipal komunal. 
Tabel 4.3. Hasil Polution Index IPAL komunal

\begin{tabular}{|c|c|c|c|c|c|c|}
\hline No & Parameter & Satuan & $\mathbf{C i}$ & LiX & $\mathrm{Ci} / \mathrm{LiX}$ & (Ci/LiX)baru \\
\hline 1 & 2 & 3 & 4 & 5 & $6=4 / 5$ & 7 \\
\hline 1 & $\mathrm{pH}$ & - & 7,59 & $6--9$ & - & 0,060 \\
\hline 2 & Temperatur & ${ }^{\circ} \mathrm{C}$ & 25 & 27 & 0,926 & 0,926 \\
\hline 3 & BOD & $\mathrm{mg} / \mathrm{L}$ & 80,61 & 75 & 1,075 & 1,157 \\
\hline 4 & $\mathrm{COD}$ & $\mathrm{mg} / \mathrm{L}$ & 121,85 & 200 & 0,609 & 0,609 \\
\hline 5 & TSS & $\mathrm{mg} / \mathrm{L}$ & 132 & 1000 & 0,132 & 0,132 \\
\hline 6 & Kekeruhan & NTU & 11,4 & 5 & 2,280 & 2,790 \\
\hline \multicolumn{6}{|c|}{ Jumlah } & 5,673 \\
\hline \multicolumn{6}{|c|}{ Rerata } & 0,946 \\
\hline \multicolumn{6}{|c|}{ Max } & 2,790 \\
\hline \multicolumn{6}{|c|}{ PI } & 2,083 \\
\hline \multicolumn{6}{|c|}{ Keterangan } & Hasil \\
\hline \multicolumn{4}{|c|}{$0<\mathrm{PI} \leq 1$} & \multicolumn{2}{|c|}{ Sangat Baik } & \multirow{4}{*}{ Ringan / Baik } \\
\hline \multicolumn{4}{|c|}{$1<\mathrm{PI} \leq 5$} & \multicolumn{2}{|c|}{ Ringan / Baik } & \\
\hline \multicolumn{4}{|c|}{$5<\mathrm{PI} \leq 10$} & \multicolumn{2}{|c|}{ Sedang } & \\
\hline \multicolumn{4}{|c|}{ PI $>10$} & \multicolumn{2}{|c|}{ Berat / Buruk } & \\
\hline
\end{tabular}

Sumber: Hasil Analisis Data,2015

Dari hasil Tabel 4.3, dapat dikatakan bahwa hasil kualitas uji laboratorium dengan hasil ringan atau baik. Namun, penanganan teknis harus diperkuat dan lebih mandiri dalam proses pengoperasian oleh masyarakat (Farahdiba, 2015 dan Puspita, 2008), karena bila tidak dikendalikan secara bekala akan terjadi akibat yang tidak diinginkan pada kualitas hasil keluaran IPAL tersebut.

Pengembangan teknologi sanitasi di Dusun Mendak sudah cukup baik, namun dalam kondisi tertentu masih terdapat adanya permasalahan. Timbulan sampah yang timbul di sekitar inlet akan semakin menumpuk dan akan mempengaruhi kondisi IPAL di tahun yang akan datang. Sehingga, sosialisasi diperlukan untuk meningkatkan kesadaran akan pentingnya menjaga lingkungan terutama dalam lingkup rumah tangga. Keberlanjutan IPAL seharusnya melihat dari aspek sosial, yaitu dari peran serta masyarakat. Selain itu, aspek ekonomi dengan adanya kemampuan warga untuk membayar dan aspek lingkungan dan teknis yang keseluruhannya saling berhubungan (Puspita, 2008).

Teknologi tambahan juga diperlukan untuk mengoptimalkan dan memanfaatkan kembali effluent IPAL. Teknologi yang dapat di upayakan guna pengembangan yakni untuk sarana pengairan untuk lahan pekarangan atau lahan pertanian, dengan dibuatkan wetland sebagai lahan serapan dan lahan sebagai media filter (Said, 2003). Selain itu, pembuatan kolam budidaya ikan yang dilanjutkan air hasil budidaya ikan terebut sebagai air untuk pengairan lahan pertanian agar hasil keluaran lebih baik dan tidak mencemari lingkungan dan badan air sekitar IPAL. 


\section{KESIMPULAN DAN SARAN}

\subsection{Kesimpulan}

Kesimpulan yang dapat diambil dari penelitian ini adalah

Hasil effluent yang dihasilkan dari IPAL Komunal SANIMAS yang didirikan oleh Dinas Pekerjaan Umum Provinsi Daerah Istimewa Yogyakarta adalah dalam keadaan baik. Namun perlu dilakukan sosialisasi tambahan terkait mengenai kebiasaan membuang sampah di rumah tangga. Pengoperasian IPAL yang dikelola secara mandiri dan terpogram menjadi salah satu bentuk kesuksesan keberlanjutan sanitasi. Oleh karena itu permberdayaan masyarakat harus ditingkatkan untuk mencapai kualitas lingkungan yang baik. Serta pentingnya peran serta dan kemandirian masyarakat untuk aktif dalam pemeliharaan dan pengelolaan sarana dan prasarana IPAL komunal SANIMAS.

\subsection{Saran}

Pada penelitian ini disarankan:

1. Meningkatkan kesadaran dan peran serta masyarakat untuk tidak membuang limbah sembarangan pada saluran menuju IPAL komunal.

2. Meningkatkan operasional kerja dengan lebih ketat dalam kontrol influent dan effluent IPAL komunal.

3. Memaksimalkan teknologi tambahan (cont. Wetland) sebagai media pengembangan dan pemaksimalan kualitas effluent sebelum dibuang kebadan air.

4. Bekerjasama dengan instansi atau berkomunikasi aktif dengan pihak DPUP ESDM dalam upaya kontroling IPAL komunal secara berkala paling tidak 1 bulan sekali untuk upaya pemaksimalan kualitas air keluaran.

\section{DAFTAR PUSTAKA}

BPPT (Badan pengkajian dan penerapan teknologi). 2008.Pengelolaan air limbah domestik di DKI Jakarta, Jakarta

Farahdiba (a), Aulia Ulfah., Ramdhaniati ,Annisa., Soedjono ,Eddy S.,2014. Teknologi Dan Manajemen Program Biogas sebagai Salah Satu Energi Alternatif yang Berkelanjutan di Kabupaten Malang. Jurnal Inovasi dan Teknologi Lingkungan. Jurnal Sains dan Teknologi Lingkungan . ISSN: 2085-1227. Volume 6, Nomor 1, Januari 2014 Hal. 48-62. 
Farahdiba (b), Aulia Ulfah., Ramdhaniati, Annisa., Soedjono, Eddy.S. 2014. Pengembangan Teknologi Air Bersih Masyarakat dalam Rangkaian Percepatan MDG's 2015 di Kabupaten Malang. Jurnal Sains dan Teknologi. Volume 6 Nomor, ISSN: 2085-1227.

Farahdiba, Aulia Ulfah., Ramdhaniati, Annisa., Soedjono, Eddy.S. Rubi, Renung. 2015 Evaluasi Teknologi Sanitasi Masyarakat Dalam Percepatan Pencapaian Sanitasi 100\% Tahun 2019 Kabupaten Malang. Jurnal Teknologi. Vol.8 No.1. 30-36. ISSN 2338-6711. $30-36$

Hammer,M.J., 1985.Water Supply and Pollution Control. Haper \& Row, New York

Haris, M. 2007. Studi Kinerja Unit Pengolahan Air Limbah Anaerobik Baffled Reactor (ABR) Pada Program SANIMAS di Mojokerto. Jurusan Teknik Lingkungan FTSP ITS.

Kusnoputranto, H, 1983.Studi Pencemaran Bakteriologis Kakus Cubluk terhadap air tanah di wilayah Kecamatan Kebayoran Lama Jakarta Selatan.Fakultas Kesehatan Masyarakat UI, Jakarta

Mahida, U. 1986, Pencemaran Air dan Pemanfaatan Limbah Industri, Rajawali Jakarta

Puspita, Indriana Widyasari. 2008. Peran Serta Masyarakat dalam Pengelolaan Limbah Kelurahan Jomblang Kota semarang. Universitas Diponegoro : Semarang

Said, Nusa Idaman, 2003, Teknologi Pengolahan Air Limbah Secara Anaerob dan Aerob menggunakan Biofilter, BPPT, Jakarta

Said, Nusa Idaman. 1995. Sistem Pengolahan Air Limbah Rumah Tangga Skala Individual Tangki Septik Filter Up Flow. Pusat Penerapan dan Pengkajian Teknologi Lingkungan, BPPT, Jakarta

Sugiharto, 1987. Dasar dasar Pengelolaan Air Limbah, Penerbit Universitas Indonesia, Jakarta 